\title{
Pathological Diversity of Gastric Cancer from the Viewpoint of Background Condition
}

\author{
Hiroyuki Abe Tetsuo Ushiku \\ Department of Pathology, Graduate School of Medicine, The University of Tokyo, Tokyo, Japan
}

\author{
Keywords \\ Gastric cancer - Helicobacter pylori - Autoimmune gastritis . \\ Hereditary gastric cancer syndrome
}

\begin{abstract}
Background: The prevalence of Helicobacter pylori infection and chronic atrophic gastritis is decreasing in Japan, which has led to a decline in the incidence of gastric cancer. However, there are various subtypes of gastric cancer that arise from the background mucosa without $H$. pylori infection, and their histological characteristics are distinct from those of gastric cancer with chronic atrophic gastritis. Summary: In this review, after a brief overview of conventional gastric carcinoma with $H$. pylori infection, including its molecular classification, histological characteristics of gastric cancer after eradicating $H$. pylori are described. The clinicopathological characteristics of gastric cancer independent of $H$. pylori infection are then explained. Autoimmune gastritis (type A gastritis) increases the risk of gastric adenocarcinoma and neuroendocrine tumors. Gastric carcinoma without $H$. pylori infection has various histological subtypes, including fundic gland-type adenocarcinoma (oxyntic gland adenoma), foveolar-type adenocarcinoma/adenoma, signet ring cell carci-
\end{abstract}

noma, and adenocarcinoma of the esophagogastric junction. In addition, some familial gastric cancer syndromes, including hereditary diffuse gastric cancer, familial adenomatous polyposis, and gastric adenocarcinoma and proximal polyposis of the stomach, are also discussed. Key Messages: Although the incidence of gastric cancer will decrease in the near future, the diversity of gastric cancer pathology will be enhanced because $H$. pylori-negative gastric cancer will have a significant impact on the clinical practice guidelines for gastric cancer. Gastroenterologists and pathologists should be aware of the morphological diversity of $H$. pylorinegative gastric cancer, and attention should be paid to the status of the background gastric mucosa while examining gastric cancer.

(c) 2021 The Author(s).

Published by S. Karger AG, Basel

\section{Introduction}

Helicobacter pylori infection is a strong risk factor for gastric cancer, and most gastric cancers arise from the mucosa with chronic atrophic gastritis induced by $H$. $p y$ lori infection. However, the prevalence of $H$. pylori infection in Japan is decreasing, especially in the younger gen-

$\begin{array}{ll}\text { karger@karger.com } & \begin{array}{l}\text { (c) } 2021 \text { The Author(s). } \\ \text { Published by S. Karger AG, Basel } \\ \text { www.karger.com/dig }\end{array} \\ \text { Karger } & \begin{array}{l}\text { This is an Open Access article licensed under the Creative Commons } \\ \text { Attribution-NonCommercial-4.0 International License (CC BY-NC) } \\ \text { (http://www.karger.com/Services/OpenAccessLicense), applicable to } \\ \text { the online version of the article only. Usage and distribution for com- } \\ \text { mercial purposes requires written permission. }\end{array}\end{array}$

Correspondence to:

Hiroyuki Abe, hiabe-tky@umin.ac.jp 
eration [1]. In addition, because $H$. pylori eradication therapy has been widely used, the number of patients with active $H$. pylori infection is now declining. Pathogenesis and histology of gastric cancer vary widely depending on the status of the background gastric mucosa. Carcinoma arising from the gastric mucosa without $H$. pylori infection will be of increasing importance in the near future, although it is rare compared to carcinoma with $H$. pylori infection. In this short review, we have summarized the pathological diversity of gastric cancer in $H$. pylori-infected and $H$. pylori-uninfected gastric mucosa.

\section{Gastric Carcinoma Arising from H. pylori-Infected Gastric Mucosa}

Most gastric carcinomas arise from chronic gastritis and intestinal metaplasia (IM) induced by $H$. pylori infection. Histological diversity was observed even within carcinoma with $H$. pylori infection. According to Laurén's classification [2], gastric cancer is classified into intestinal, diffuse, and mixed types. Japanese classification of gastric carcinoma proposed by the Japanese Gastric Cancer Association defines 5 common types (papillary adenocarcinoma, tubular adenocarcinoma, poorly differentiated adenocarcinoma, signet ring cell carcinoma, and mucinous carcinoma) and various special types [3]. The WHO classification of tumors (5th edition) includes tubular adenocarcinoma, papillary adenocarcinoma, poorly cohesive carcinoma (including signet ring cell carcinoma and other subtypes), mucinous adenocarcinoma, and mixed adenocarcinoma [4]. Gastric carcinoma with $H$. pylori infection could show various histological types of these classifications.

In 2014, the Cancer Genome Atlas Research Network proposed 4 molecular subtypes of gastric cancer (tumors

Fig. 1. Gastric adenocarcinoma with $H$. pylori infection. a, b Welldifferentiated tubular adenocarcinoma. In low-power view (a), the tumor is well defined. In high-power view (b), well-formed glands are noted. The chromosomal instability molecular subtype is common in such a histology. c, d Poorly differentiated adenocarcinoma. In low-power view (c), the tumor boundary is unclear. In high-power view (d), poorly cohesive carcinoma cells have diffusely invaded the gastric wall with prominent fibrous stroma. The genomically stable molecular subtype is common in this histology. e Tumors with microsatellite instability. Prominent intratumoral lymphocytic infiltration is noted. f Immunohistochemistry of MLH1 in the same tumor as (e). Expression of MLH1 is lost with chromosomal instability [CIN], genomically stable tumors [GS], microsatellite unstable tumors [MSI], and tumors positive for Epstein-Barr virus [EBV]) [5]. Histologically, CIN is enriched with the intestinal-type Laurén's classification (Fig. 1a, b), while GS usually shows diffuse-type histology (Fig. 1c, d). MSI shows a hypermutation phenotype with deficient mismatch repair protein expression, which can be detected by immunohistochemistry (Fig. 1e, f). Most MSI tumors are sporadic and harbor promoter deoxyribonucleic acid (DNA) methylation of the MLH1 gene, while some MSI tumors are hereditary (Lynch syndrome) with germline pathogenic variants in mismatch repair genes. Most gastric carcinomas in patients with Lynch syndrome develop from gastric mucosa with chronic atrophic gastritis, similar to sporadic cases [6]. EBV tumors harbor EBV in each tumor cell, which can be detected with Epstein-Barr encoded small RNA-in situ hybridization (Fig. 1g). EBV tumors show a hypermethylated epigenotype with genome-wide DNA methylation [7]. However, DNA methylation is not a random process, and the $M L H 1$ gene is not methylated in EBV tumors; thus, MSI and EBV infection are mutually exclusive. Although EBV infection plays a crucial role in the carcinogenesis of EBV tumors, most EBV tumors arise from chronic atrophic gastritis with $H$. pylori infection, which suggests that chronic inflammation in the gastric mucosa is necessary to establish EBV infection in gastric epithelial cells [8]. Because EBV-infected early gastric carcinoma (pT1) has low incidence of lymph node metastasis, expanding indication for endoscopic submucosal dissection might be considered for EBV-infected carcinomas $[9,10]$. Both MSI and EBV tumors have dense lymphocytic infiltration within the tumor (hot antitumor immunity in the tumor microenvironment) and are sensitive to immune checkpoint therapy [11].

in tumor cells. Lymphocytes in the stroma are positive for MLH1 and served as internal controls. g Tumors positive for EpsteinBarr virus. The tumor located in the mucosa and irregularly fused glands are noted. The morphological pattern is called as "lacepattern." In the tumor glands and stroma, conspicuous lymphocytic infiltration is noted. Each tumor cell is positive for EpsteinBarr encoded small RNA-in situ hybridization (inset). $\mathbf{h}$ Welldifferentiated intramucosal adenocarcinoma after $H$. pylori eradication. The surface is covered by epithelium with low-grade atypia (white arrowhead) and nonneoplastic epithelia (black arrowhead). a-e, $\mathbf{g}, \mathbf{h}$ Hematoxylin and eosin stain; $\mathbf{f}$ immunohistochemistry of MLH1.
Abe/Ushiku 

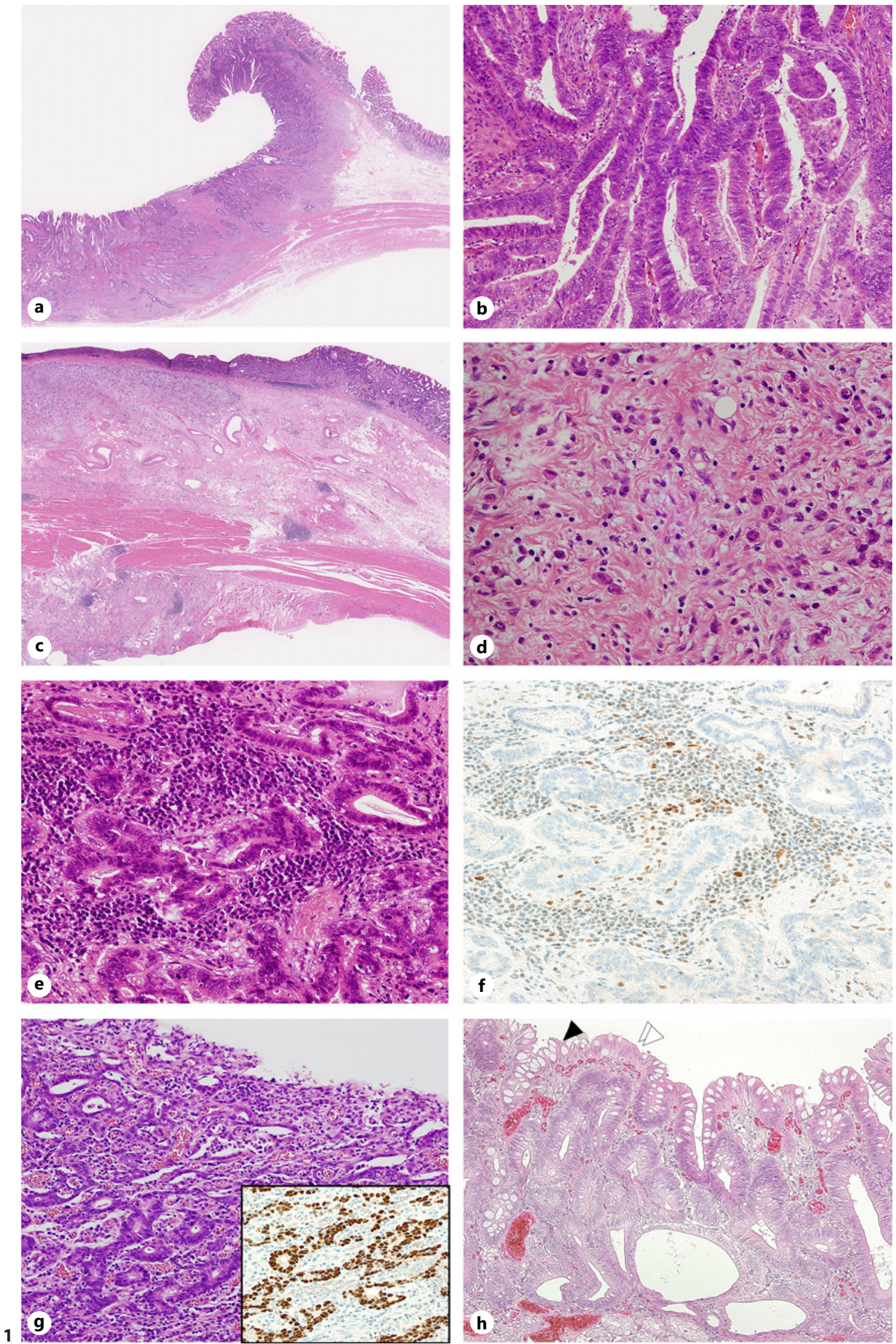


\section{Gastric Carcinoma after Eradicating H. pylori}

Although eradicating $H$. pylori reduces the risk of gastric cancer, detection of gastric cancer in follow-up gastroscopy after eradication is common. These carcinomas might be present before eradication and remain undetected because of their small size or may develop after eradication. Histological characteristics are similar to those of carcinoma with $H$. pylori infection. However, in intramucosal carcinoma with the histology of intestinal-type Laurén's classification, the surface of the carcinoma is frequently covered by epithelial cells with weak nuclear atypia, which is called "epithelium with low-grade atypia" [12] or "nonneoplastic epithelia" [13] (Fig. 1h). Carcinoma covered with epithelium with low-grade atypia or nonneoplastic epithelia might be challenging to detect endoscopically because surface differentiation of early gastric cancer induces "gastritislike appearance" by magnifying narrow-band imaging endoscopy, which was characterized by uniform papillae and tubular pits bordered by a whitish backward scattering and regular or faint microvessels. Because these features resembled surrounding nonneoplastic mucosa, the lesions displayed unclear demarcation [14]. Endoscopists should be aware of the endoscopic and histological changes in gastric carcinoma after eradicating $H$. pylori.

\section{Gastric Carcinoma with Autoimmune Atrophic Gastritis}

Chronic autoimmune gastritis (AIG), also known as type A gastritis, was proposed by Strickland and Mackay [15] and characterized by atrophy and metaplasia in the body and fundus of the stomach, in contrast to $H$. pylori gastritis (type B gastritis), which induces atrophy predominantly in the antrum. Chronic autoimmune inflammation induces loss of parietal cells and chief cells in the fundic glands. They are replaced by goblet cells (IM), pyloric glands without pepsinogen-I expression, or pseudo-pyloric glands with pepsinogen-I expression. Some researchers call pyloric/pseudo-pyloric gland metaplasia as spasmolytic polypeptide-expressing metaplasia (SPEM), which is characterized by trefoil factor family 2 expression. However, SPEM is originally proposed in animal models, and pyloric/pseudo-pyloric gland metaplasia does not always express trefoil factor family 2 [16]. IM and pyloric/pseudo-pyloric gland metaplasia in the stomach induce a reduction in vitamin $B_{12}$ absorption and pernicious anemia [17].

In patients with AIG, the risk of adenocarcinoma and neuroendocrine tumors is higher than that in the general population. Intestinal-type adenocarcinoma usually develops in the background atrophic mucosa with metaplasia, including both IM and SPEM [17]. A systematic review demonstrated that the incidence of gastric cancer in pernicious anemia is $0.27 \%$ per person-years, with an approximate 7 -fold relative risk of gastric cancer in patients with pernicious anemia [18]. Concurrent $H$. pylori infection may increase the risk of cancer.

Neuroendocrine tumors in the stomach are classified into 3 subtypes which have distinct background condition and clinicopathological features [19]. Neuroendocrine tumor in the background of AIG is classified as type I. AIG upregulates gastrin production by $G$ cells in the antrum due to the loss of parietal cells and decreased acid secretion. Gastrin stimulates enterochromaffin-like cells in the body and fundus of the stomach and promotes enterochromaffin-like cell proliferation. Neuroendocrine tumors in the background of AIG might be multiple but usually small $(<2 \mathrm{~cm})$ without metastasis. Type I neuroendocrine tumors are thought to have low malignant po-
Fig. 2. Gastric adenocarcinoma without $H$. pylori infection. a Low-power view of adenocarcinoma of the fundic gland type. Irregular fused glands are observed on the right. b High-power view of adenocarcinoma of the fundic gland type. The nuclei show a uniform small round shape; however, the density of the nuclei is high. The cytoplasm is a little basophilic. Tumor cells are positive for MUC6 (left inset) and pepsinogen-I (right inset). c Lowpower view of foveolar adenocarcinoma (raspberry-type). A protruding mass is formed from the fundic gland mucosa without atrophy. Congestion is noted in the stroma, which appears reddish endoscopically. d High-power view of raspberry-type adenocarcinoma. Surface foveolar epithelium has enlarged nuclei with disorderly arrangement. e, f Signet ring cell carcinoma. In lowpower view (e), tumor cells proliferate in the mucosa (arrowheads). Background mucosa is composed of fundic glands without intestinal metaplasia. In high-power view (f), poorly cohesive carcinoma cells with prominent mucin and eccentric nuclei are observed near the proliferative zone of fundic gland mucosa. g, h Fundic gland polyp with dysplasia in a patient with familial adenomatous polyposis. In low-power view $(\mathbf{g})$, proliferation of slightly dilated fundic glands is noted, which are covered by the foveolar epithelium. In high-power view, the surface foveolar epithelium has enlarged nuclei with condensed chromatin. a-h Hematoxylin and eosin stain.
(For figure see next page.)
48

Digestion 2022;103:45-53

DOI: $10.1159 / 000519337$
Abe/Ushiku 

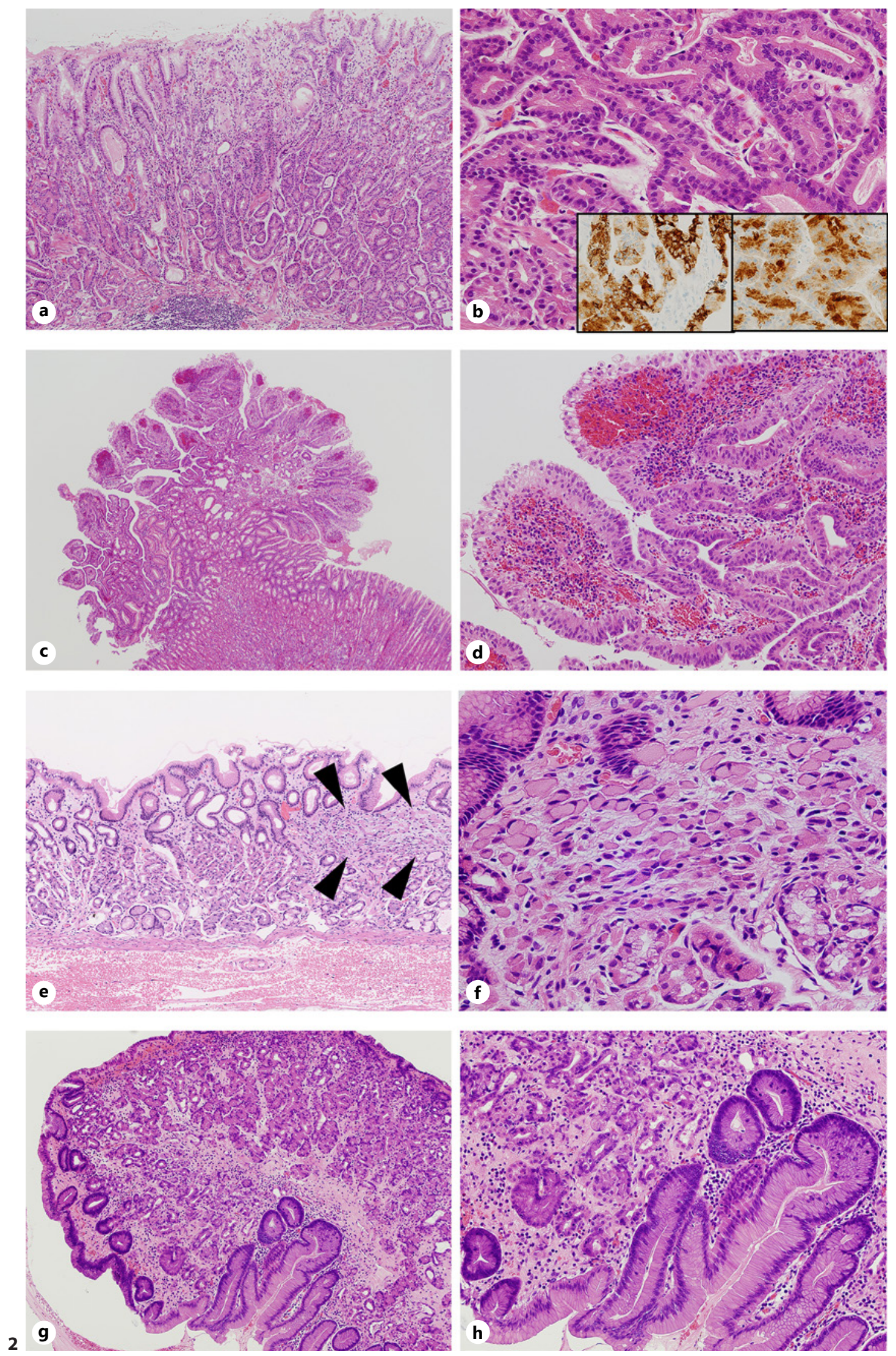
tential compared with type II (neuroendocrine tumors induced by gastrinoma) or type III (sporadic neuroendocrine tumors without hypergastrinemia) [20].

\section{Gastric Carcinoma Arising from Mucosa without $\boldsymbol{H}$. pylori Infection}

In this section, gastric mucosa without $H$. pylori infection indicates no history of present or past $H$. pylori infection, and the gastric mucosa is well preserved without atrophic gastritis or IM. Although these carcinomas are relatively rare compared with $H$. pylori-related gastric carcinomas, various histological types of carcinomas have been proposed to date. Most of them showed a gastric-type mucin phenotype.

\section{Adenocarcinoma of Fundic Gland Type/Oxyntic Gland Adenoma}

Adenocarcinoma of fundic gland type (FGA)/oxyntic gland adenoma is a well-differentiated adenocarcinoma comprising pale gray-blue, basophilic columnar cells with mild nuclear atypia and irregularly fused glands (Fig. 2a, b). Carcinoma cells usually express MUC6 and pepsinogen-I diffusely and $\mathrm{H}^{+} / \mathrm{K}^{+}$ATPase focally, exhibiting differentiation predominantly toward chief cells and focally toward parietal cells. FGA is usually located in the upper third of the stomach and shows superficial depressed (0-IIc) or superficial elevated (0-IIa) gross type [21]. FGA is a less-aggressive neoplasm, although invasion into the submucosa is not rare. Invasion into the muscular layer or subserosa and metastases to the lymph nodes are extremely rare, but 1 case of advanced gastric cancer was reported in which FGA gradually transitioned into irregular tubules and small clusters with invasion into subserosa and metastasis to the regional lymph node [22]. In some cases, carcinoma cells differentiate into foveolar epithelium or mucous neck cells and/or highgrade nuclear or architectural abnormalities. These tumors are called as "fundic gland mucosal type," which was originally proposed in the Japanese literature by Tanabe and colleagues in 2015. In such cases, tumors are thought to have relatively high malignant potential [23].

\section{Foveolar-Type Adenocarcinoma/Adenoma}

Neoplasms showing foveolar differentiation in the gastric mucosa without $H$. pylori infection are classified into 3 subtypes: whitish flat-elevated type, raspberry-like appearance type, and foveolar-type adenoma in the fundic gland polyp. Endoscopically, the whitish flat-elevated type is observed as a laterally spreading lesion with a whitish appearance. Histologically, the tumor has villous or papillary structures comprising dysplastic columnar cells with clear cytoplasm. When nuclear atypia is minimal, it is challenging to differentiate foveolar-type adenocarcinoma from foveolar-type hyperplastic polyps. However, hyperplastic polyps usually arise from the background mucosa with chronic gastritis and $H$. pylori infection. Immunohistochemistry showed that the surface of the tumor was positive for MUC5AC, whereas the deeper area of the mucosa was positive for MUC6. Pepsinogen-I and MUC2 were negative [24].

The raspberry-like appearance type is more common than the whitish flat-elevated type. Endoscopically, the tumor presents as small reddish protrusions with a fine granular surface, showing a raspberry-like appearance. These neoplasms are located predominantly in the upper or middle part of the stomach, without a present or past history of $H$. pylori infection. Histologically, tumor cells showed differentiation toward the foveolar epithelium and formed irregular glands or papillary structures (Fig. 2c, d). Cell density increased, and the nuclei showed loss of polarity; however, no stromal invasion was identified [25]. Immunohistochemically, tumor cells were positive for MUC5AC and negative for MUC6, MUC2, or CD10. Although the Ki67 index was relatively high, p53-positive cells were scattered in the tumor (wild-type pattern) [26]. Although some reports describe these neoplasms as adenocarcinoma, some authors describe these neoplasms as "adenoma" because of their low malignant potential [27].

Foveolar-type adenoma in the fundic gland polyp is frequently observed in patients with familial adenomatous polyposis or gastric adenocarcinoma and proximal polyposis of the stomach and discussed later in the section of hereditary cancer syndromes. Although extremely rare, sporadic cases are occasionally experienced, none of which is reported to progress to gastric cancer [28].

\section{Signet Ring Cell Carcinoma}

Signet ring cell carcinoma is one of the most frequent histological types of $H$. pylori-negative early gastric cancer $[24,29]$. Endoscopically, signet ring cell carcinoma is a whitish lesion with a slightly depressed appearance (type 0-IIc). Signet ring cells have rich cytoplasmic mucin and small eccentric nuclei (Fig. 2e, f). In its early stage, signet ring cells proliferate predominantly in the proliferative zone (near the mucous neck cells) of the gastric mucosa. After progression, carcinoma cells spread through the full thickness of the mucosal layer and finally invade the submucosa and deeper areas as diffuse-type
Abe/Ushiku 
gastric cancer. Signet ring cell carcinoma of an $H$. pylorinegative stomach is less aggressive than that of an $H$. $p y$ lori-positive stomach because in $H$. pylori-negative cases, carcinoma cells are frequently confined to the proliferative layer and show low proliferative activity [30].

\section{Adenocarcinoma in the Esophagogastric Junction}

Atrophic gastritis caused by $H$. pylori usually spreads from the antrum to the body of the stomach. Gastric cardia is least frequently affected by atrophic gastritis and IM. A previous study demonstrated that esophagogastric junction adenocarcinoma is less frequently associated with $H$. pylori infection and atrophic gastritis compared with adenocarcinoma of the distal stomach, although histologically, the intestinal-type Laurén's classification is more common in the esophagogastric junction [31]. In addition, adenocarcinoma of the esophagogastric junction frequently shows the gastric mucin phenotype compared with distal gastric cancer [32]. These observations suggest that some esophagogastric junction adenocarcinomas, such as Barrett's adenocarcinoma of the esophagus, are independent of $H$. pylori infection or atrophic gastritis. As gastroesophageal reflux disease and Barrett's esophagus are increasing due to a decrease in $H$. pylori infection and a westernized lifestyle in Japan, esophagogastric junction adenocarcinoma is thought to increase in the near future [33].

\section{Gastric Carcinoma with Hereditary Cancer Syndromes}

Some hereditary cancer syndromes induce gastric cancer in younger patients without $H$. pylori infection. In this section, certain familial gastric cancer syndromes are described.

\section{Hereditary Diffuse Gastric Cancer}

HDGC is characterized by a high risk of developing diffuse-type gastric cancer. In the clinical diagnostic criteria, family history or carcinoma developed in younger patients is emphasized. In $30-50 \%$ of the patients, germline pathogenic variants of $C D H 1$, which encodes E-cadherin protein, were detected. Histological evaluation of the resected stomach revealed multiple signet ring cell carcinomas or poorly differentiated adenocarcinomas in the mucosal layer. Most carcinomas arise from the fundic gland mucosa; however, some originate from the pyloric gland mucosa. Immunohistochemically, carcinoma cells show complete loss or reduction in E-cadherin expression [34]. In patients with HDGC, signet ring cells some- times proliferate within the basement membrane with replacement of the gastric epithelium or pagetoid spread beneath the gastric epithelial cells, which is called signet ring cell carcinoma in situ. The lesion is thought to be a precursor of signet ring cell carcinoma; however, in situ signet ring cells are not detected in cases of sporadic signet ring cell carcinoma [35].

\section{Familial Adenomatous Polyposis}

FAP is inherited in an autosomal dominant fashion and is caused by the germline pathogenic variant of the adenomatous polyposis coli (APC) gene, resulting in adenomatous polyposis of the colon and a high risk of colorectal cancer. In patients with FAP, numerous fundic gland polyps develop in the proximal stomach, some of which may show low-grade dysplasia (Fig. 2g, h). Although fundic gland polyposis is observed in non-FAP patients using proton pump inhibitors, no APC gene mutation is observed, and dysplasia is not associated with these sporadic polyps. Pyloric gland adenomas have also developed in FAP. Intestinal-type tubular adenomas are rare in Western countries but more common in Asian countries, probably due to $H$. pylori infection [36]. In fact, several studies reported that atrophic gastritis is a main risk factor of gastric adenoma/carcinoma in FAP patients [37-39]. The risk of gastric adenocarcinoma is also increased in patients with FAP, especially those with a large number of polyps (carpeting polyps) or larger polyps [40].

\section{Gastric Adenocarcinoma and Proximal Polyposis of the Stomach}

GAPPS is a rare hereditary cancer syndrome characterized by a carpet of $>100$ polyps in the body or fundus of the stomach with antral sparing. However, no colorectal polyposis is observed in GAPPS. In addition to multiple fundic gland polyps, hyperproliferative aberrant pits, in which disorganized proliferation of specialized/oxyntic glands is high in the mucosa involving the attenuated foveolar region around the gastric pits, forming a polypoid lesion, are frequently observed in GAPPS. Neoplasms such as adenoma, flat dysplasia, or tubular adenocarcinoma may develop in GAPPS. All neoplastic lesions showed a morphologically and immunohistochemically gastric phenotype (positive for MUC5AC). Recently, the pathogenic variant of promoter $1 \mathrm{~B}$ of the $A P C$ gene, which decreases the expression of the APC gene, was reported in GAPPS [41]. As promoter 1A, an alternative promoter for promoter $1 \mathrm{~B}$ of the APC gene, is inactivated by methylation in the gastric mucosa but not in the colonic mucosa, colonic polyposis is not observed in GAPPS [42]. 


\section{Conclusion}

A recent drastic decrease in the prevalence of $H . p y$ lori infection in Japan and other developed countries will change the landscape of gastric cancer morphology. Although gastric carcinomas without $H$. pylori infection are a rare neoplasm compared with $H$. pylori-positive "conventional" gastric cancer, endoscopists and pathologists should get familiar with the various characteristics of gastric cancer that develop from $H$. pylori-negative gastric mucosa.

\section{Acknowledgment}

We would like to thank Editage (www.editage.com) for English language editing.

\section{Conflict of Interest Statement}

The authors have no conflicts of interest to declare.

\section{Funding Sources}

No funding was received for this study.

\section{Author Contributions}

H.A. wrote the manuscript. T.U. critically read the manuscript and gave some advice. All authors read and approved the final version of the manuscript.

\section{References}

1 Inoue M. Changing epidemiology of Helicobacter pylori in Japan. Gastric Cancer. 2017; 20(Suppl 1):3-7.

2 Lauren P. The two histological main types of gastric carcinoma: diffuse and so-called intestinal-type carcinoma. an attempt at a histoclinical classification. Acta Pathol Microbiol Scand. 1965;64:31-49.

3 Japanese Gastric Cancer Association. Japanese classification of gastric carcinoma: 3rd English edition. Gastric Cancer. 2011;14(2): 101-12.

4 Carneiro F, Fukayama M, Grabsch HI, Yasui W. Gastric adenocarcinoma: WHO classification of tumours. 5th ed.Digestive system tumours. Lyon: International Agency for Research on Cancer; 2019. p. 85-95.

5 Bass AJ, Thorsson V, Shmulevich I, Reynolds SM, Miller M, Bernard B, et al. Comprehensive molecular characterization of gastric adenocarcinoma. Nature. 2014;513(7517):2029.

6 Cho H, Yamada M, Sekine S, Tanabe N, Ushiama M, Hirata $M$, et al. Gastric cancer is highly prevalent in Lynch syndrome patients with atrophic gastritis. Gastric Cancer. 2021; 24(2):283-91.

7 Matsusaka K, Kaneda A, Nagae G, Ushiku T, Kikuchi Y, Hino R, et al. Classification of Epstein-Barr virus-positive gastric cancers by definition of DNA methylation epigenotypes. Cancer Res. 2011 Dec;71(23):7187-97.

8 Yanai H, Murakami T, Yoshiyama H, Takeuchi H, Nishikawa J, Nakamura H, et al. Epstein-Barr virus-associated gastric carcinoma and atrophic gastritis. J Clin Gastroenterol. 1999 Jul;29(1):39-43.

9 Tsuji Y, Ushiku T, Shinozaki T, Yamashita H, Seto Y, Fukayama M, et al. Risk for lymph node metastasis in Epstein-Barr virus-associ- ated gastric carcinoma with submucosal invasion. Dig Endosc. 2021 May;33(4):592-7.

10 Osumi H, Kawachi H, Yoshio T, Fujisaki J. Clinical impact of Epstein-Barr virus status on the incidence of lymph node metastasis in early gastric cancer. Dig Endosc. 2020;32(3): 316-22.

11 Kim ST, Cristescu R, Bass AJ, Kim KM, Odegaard JI, Kim K, et al. Comprehensive molecular characterization of clinical responses to PD-1 inhibition in metastatic gastric cancer. Nat Med. 2018;24(9):1449-58.

12 Kitamura Y, Ito M, Matsuo T, Boda T, Oka S, Yoshihara M, et al. Characteristic epithelium with low-grade atypia appears on the surface of gastric cancer after successful Helicobacter pylori eradication therapy. Helicobacter. 2014;19(4):289-95.

13 Saka A, Yagi K, Nimura S. Endoscopic and histological features of gastric cancers after successful Helicobacter pylori eradication therapy. Gastric Cancer. 2016;19(2):524-30.

14 Kobayashi M, Hashimoto S, Nishikura K, Mizuno K, Takeuchi M, Sato Y, et al. Magnifying narrow-band imaging of surface maturation in early differentiated-type gastric cancers after Helicobacter pylori eradication. J Gastroenterol. 2013;48(12):1332-42.

15 Strickland RG, Mackay IR. A reappraisal of the nature and significance of chronic atrophic gastritis. Am J Dig Dis. 1973;18(5):426-40.

16 Wada Y, Nakajima S, Kushima R, Takemura S, Mori N, Hasegawa H, et al. Pyloric, pseudopyloric, and spasmolytic polypeptide-expressing metaplasias in autoimmune gastritis : a case series of 22 Japanese patients. Virchows Arch. 2021;479:169-78.

17 Bizzaro N, Antico A, Villalta D. Autoimmunity and gastric cancer. Int J Mol Sci. 2018; 19(2):1-14.
18 Vannella L, Lahner E, Osborn J, Annibale B. Systematic review: gastric cancer incidence in pernicious anaemia. Aliment Pharmacol Ther. 2013;37(4):375-82.

19 Rindi G, Luinetti O, Cornaggia M, Capella C, Solcia E. Three subtypes of gastric argyrophil carcinoid and the gastric neuroendocrine carcinoma: a clinicopathologic study. Gastroenterology. 1993 Apr;104(4):994-1006.

20 Crosby DA, Donohoe CL, Fitzgerald L, Muldoon C, Hayes B, O'Toole D, et al. Gastric neuroendocrine tumours. Dig Surg. 2012; 29(4):331-48.

21 Ueyama H, Yao T, Nakashima Y, Hirakawa K, Oshiro Y, Hirahashi M, et al. Gastric adenocarcinoma of fundic gland type (chief cell predominant type): proposal for a new entity of gastric adenocarcinoma. Am J Surg Pathol. 2010;34(5):609-19.

22 Okumura Y, Takamatsu M, Ohashi M, Yamamoto Y, Yamamoto N, Kawachi H, et al. Gastric adenocarcinoma of fundic gland type with aggressive transformation and lymph node metastasis: a case report. J Gastric Cancer. 2018;18(4):409-16.

23 Ushiku T, Kunita A, Kuroda R, ShinozakiUshiku A, Yamazawa S, Tsuji Y, et al. Oxyntic gland neoplasm of the stomach: expanding the spectrum and proposal of terminology. Mod Pathol. 2020;33(2):206-16.

24 Yamada A, Kaise M, Inoshita N, Toba T, Nomura K, Kuribayashi Y, et al. Characterization of Helicobacter pylori-naïve early gastric cancers. Digestion. 2018;98(2):127-34.

25 Shibagaki K, Fukuyama C, Mikami H, Izumi D, Yamashita N, Mishiro T, et al. Gastric foveolar-type adenomas endoscopically showing a raspberry-like appearance in the Helicobacter pylori -uninfected stomach. Endosc Int Open. 2019;7(06):E784-91. 
26 Yatagai N, Ueyama H, Ikemura M, Uchida R, Utsunomiya $\mathrm{H}$, Abe D, et al. Clinicopathological and endoscopic features of raspberryshaped gastric cancer in Helicobacter pyloriuninfected patients. Digestion. 2021;102(1): 41-8.

27 Shibagaki K, Mishiro T, Fukuyama C, Takahashi Y, Itawaki A, Nonomura S. Sporadic foveolar-type gastric adenoma with a raspberry-like appearance in Helicobacter pylori: naive patients. Virchows Arch. 2021 May 27. Epub ahead of print.

28 Sekine S, Montgomery EA, Vieth M. Foveolar-type adenoma: WHO classification of tumours. 5th ed.Digestive system tumours. Lyon: International Agency for Research on Cancer; 2019. p. 79-80.

29 Sato C, Hirasawa K, Tateishi Y, Ozeki Y, Sawada A, Ikeda R, et al. Clinicopathological features of early gastric cancers arising in $\mathrm{He}-$ licobacter pylori uninfected patients. World J Gastroenterol. 2020;26(20):2618-31.

30 Horiuchi Y, Fujisaki J, Yamamoto N, Shimizu T, Miyamoto Y, Tomida H, et al. Biological behavior of the intramucosal Helicobacter pylori-negative undifferentiated-type early gastric cancer: comparison with Helicobacter pylori-positive early gastric cancer. Gastric Cancer. 2016;19(1):160-5.
31 Kamada T, Kurose H, Yamanaka Y, Manabe N, Kusunoki H, Shiotani A, et al. Relationship between gastroesophageal junction adenocarcinoma and helicobacter pylori infection in Japan. Digestion. 2012;85(4):256-60.

32 Tajima Y, Nakanishi Y, Yoshino T, Kokawa A, Kusano M, Shimoda T. Clinicopathological study of early adenocarcinoma of the gastric cardia: comparison with early adenocarcinoma of the distal stomach and esophagus. Oncology. 2001;61(1):1-9.

33 Nishi T, Makuuchi H, Ozawa S, Shimada H, Chino O. The present status and future of Barrett's esophageal adenocarcinoma in Japan. Digestion. 2019;99(2):185-90.

34 Oliveira C, Pinheiro H, Figueiredo J, Seruca $\mathrm{R}$, Carneiro F. Familial gastric cancer: genetic susceptibility, pathology, and implications for management. Lancet Oncol. 2015;16(2):e6070.

35 Tsugeno Y, Nakano K, Nakajima T, Namikawa K, Takamatsu M, Yamamoto N, et al. Histopathologic analysis of signet-ring cell carcinoma in situ in patients with hereditary diffuse gastric cancer. Am J Surg Pathol. 2020; 44(9):1204-12.

36 Brosens LA, Wood LD, Offerhaus GJ, Arnold CA, Lam-Himlin D, Giardiello FM, et al. Pathology and genetics of syndromic gastric polyps. Int J Surg Pathol. 2016;24(3): 185-99.
37 Nakamura S, Matsumoto T, Kobori Y, Iida M. Impact of Helicobacter pylori infection and mucosal atrophy on gastric lesions in patients with familial adenomatous polyposis. Gut. 2002;51(4):485-9.

38 Nakamura K, Nonaka S, Nakajima T, Yachida $\mathrm{T}$, Abe S, Sakamoto T, et al. Clinical outcomes of gastric polyps and neoplasms in patients with familial adenomatous polyposis. Endosc Int Open. 2017;5(03):E137-45.

39 Nakano K, Kawachi H, Chino A, Kita M, Arai $\mathrm{M}$, Ide D, et al. Phenotypic variations of gastric neoplasms in familial adenomatous polyposis are associated with endoscopic status of atrophic gastritis. Dig Endosc. 2020;32(4):547-56.

40 Leone PJ, Mankaney G, Sarvapelli S, Abushamma S, Lopez R, Cruise M, et al. Endoscopic and histologic features associated with gastric cancer in familial adenomatous polyposis. Gastrointest Endosc. 2019;89(5):961-8.

41 De WB, Ee H, Kumarasinghe MP. Neoplastic lesions of Gastric Adenocarcinoma and Proximal Polyposis Syndrome (GAPPS) are gastric phenotype. Am J Surg Pathol. 2018 Jan; $42(1): 1-8$.

42 Li J, Woods SL, Healey S, Beesley J, Chen X, Lee JS, et al. Point mutations in exon $1 \mathrm{~B}$ of APC reveal gastric adenocarcinoma and proximal polyposis of the stomach as a familial adenomatous polyposis variant. Am J Hum Genet. 2016;98(5):830-42. 